\title{
Specific microRNA expression during chondrogenesis of human mesenchymal stem cells
}

\author{
JIANWEI HAN*, TONGTAO YANG* ${ }^{*}$, JIE GAO*, JIACHANG WU, \\ XIUCHUN QIU, QINGYU FAN and BAOAN MA \\ Department of Orthopedic Surgery, Tangdu Hospital, Fourth Military Medical University, \\ Xi'an, Shaanxi 710038, P.R. China
}

Received September 29, 2009; Accepted November 23, 2009

DOI: 10.3892/ijmm_00000355

\begin{abstract}
Mesenchymal stem cells (MSCs) have the capacity to self-renew and differentiate into multiple cell types, but little is known about the precise mechanism of this procedure. Recent studies show that a group of short noncoding RNAs called microRNAs (miRNAs) play a key role in this procedure. However, little work has been done to determine the miRNAs which specifically regulate the differentiation of MSCs. In this study, we cultured human MSCs and chondrogenic differentiation MSCs of 3 donors, and investigated the miRNA expression profiles of MSCs and chondrogenic differentiated MSCs from 2 donors by using miRNA microarrays. We found 5 miRNAs were significantly overexpressed in chondrogenic differentiated MSCs in each sample, and 4 were further confirmed by real-time RT-PCR assay in the sample from the third independent donor. We also predicted the confirmed miRNAs corresponding to putative target genes by online software. The results indicated that the overexpressed miRNAs in chondrogenic differentiated MSCs may play a role in the procedure of MSC chondrogenesis, which offers us guidance for further studies.
\end{abstract}

\section{Introduction}

Mesenchymal stem cells (MSCs), also called mesenchymal stromal cells, present the characteristic of long-term selfrenewal and multi-lineage differentiation potential. Given appropriate cultures, MSCs are able to differentiate into different mesodermal cell lineages, including osteocytes, chondrocytes, and adipocytes $(1,2)$. With this characteristic,

Correspondence to: Dr Baoan Ma, Department of Orthopedic Surgery, Tangdu Hospital, Fourth Military Medical University, Xi'an, Shaanxi 710038, P.R. China

E-mail: gukemba@fmmu.edu.cn

*Contributed equally

Key words: mesenchymal stem cell, differentiation, microRNA, microarray
MSCs offer great hope for a variety of therapeutic applications $(3,4)$. However, MSCs are heterogeneous populations of cells and MSCs isolated from different donors present a high degree of variability (5), which makes it difficult to determine the precise mechanism of its self-renewal and multi-lineage differentiation.

MicroRNAs (miRNAs) are noncoding, short singlestranded RNAs of 18-25 nucleotides and play important roles in several biological processes post-transcriptionally $(6,7)$. After the first miRNA (lin-4) was discovered by Lee et al (8), hundreds of miRNAs have been identified in plants and animals, and many of them are highly conserved across species and tissue-specific $(9,10)$. Previous studies show that miRNAs play a key role in stem cell self-renewal, cell division and differentiation (11-15). A unique group of miRNAs have been reported to be expressed in human and mouse embryonic stem cells (ESCs), which suggest they are involved in ESC development (16-20). Due to heterogeneity of MSCs, it is difficult to determine the specific expression patterns of MSCs and their differentiated cells. Therefore, compared with ESCs, only a few studies have identified the specific miRNAs during MSC differentiation. For example, miR-143 has been reported to be involved in adipocyte differentiation through the target gene ERK5 (12), miR-125b inhibits osteoblastic differentiation of mouse mesenchymal stem cells by down-regulation of cell proliferation through targeting ErbB2/3 genes (21). Another specific miRNA, miR-140, was found to be expressed during mouse cartilage development and may function by inhibiting HDAC4, a likely co-repressor of RUNX2 (22).

In this study, we employed microarray technique to explore the expression of miRNAs during chondrogenesis of MSCs. The differentially expressed miRNAs between MSCs and chondrogenic differentiation MSCs were verified by real-time RT-PCR. We obtained 4 miRNAs up-regulated in chondrogenic differentiated MSCs. Then, we predicted their putative target genes with bioinformatic analysis, which may offer us guidance for further study.

\section{Materials and methods}

Isolation and culture of human MSCs. The three human bone marrow samples in our study were collected from patients without hematologic diseases after obtaining informed 
consent. These three samples were not collected at the same time (A: 19 years old, Chinese, male; B: 24 years old, Chinese, female; C: 26 years old, Chinese, male).

Immediately after the sample being collected, monocytes were separated from the samples by $1.073 \mathrm{~g} / \mathrm{ml}$ Percoll (Sigma) with density gradient centrifugation method. Monocytes were incubated at 5000 cells per $\mathrm{cm}^{2}$ in $25-\mathrm{cm}^{2}$ culture flasks (Falcon) consisting the medium of Low Glucose Dulbecco's modified Eagle's medium (L-DMEM, Gibco) and 15\% fetal bovine serum [FBS, (Hyclone)]. The cultures were maintained at $37^{\circ} \mathrm{C}$ in a humidified atmosphere containing $5 \%$ carbon dioxide. Culture medium changes were performed at day 5 and then twice a week. After 10-14 days of cultivation, the cells were trypsinized and re-seeded at $5 \times 10^{4}$ cells $/ \mathrm{cm}^{2}$ in new flasks. When $80 \%$ confluent, the cells were harvested and replanted with $1: 3$ proportion to expand the cells.

Phenotype analysis of MSCs. Cells at the fourth passage with $80 \%$ confluence were collected and suspended in phosphate buffered saline (PBS) at a concentration of $1 \times 10^{6}$ cells $/ \mathrm{ml}$. Mouse anti-human antibody (CD34-FITC, CD45-FITC, CD29FITC, CD44-FITC) $(5 \mu 1)$ was added into $500 \mu 1$ suspension containing $5 \times 10^{5}$ cells and the mixture was incubated for $20 \mathrm{~min}$ at room temperature. Then the cells were harvested and rinsed twice with cleaning solution (PBS $+1 \% \mathrm{FBS}+0.1 \%$ $\mathrm{NaN}_{3}$ ). The cells were suspended in $500 \mu \mathrm{l}$ of cleaning solution, which were analyzed using a flow cytometer.

Chondrogenic differentiation of MSCs. MSCs at fourth passage were detached by trypsin and washed twice with PBS. The collecting cells were re-suspended in a $15 \mathrm{ml}$ polypropylene tube (Orange) containing $1 \mathrm{ml}$ chondrogenic differentiation medium at a density of $4 \times 10^{5} / \mathrm{ml}$, centrifugated at $500 \mathrm{x}$ g for 15 min into cell mass. The cell mass was cultured at $37^{\circ} \mathrm{C}$ in a humidified atmosphere containing $5 \%$ carbon dioxide for 21 days with the medium changes twice a week. The chondrogenic medium contained high glucose Dulbecco's modified Eagle's medium (H-DMEM, Gibco), supplemented with $1 \mathrm{ng} / \mathrm{ml} \mathrm{TGF}-\beta_{1}$ (Sigma), 10-7/1 dexamethasone (Gibco), $50 \mathrm{mg} / \mathrm{l}$ vitamin C (Gibco), $6.25 \mathrm{ng} / \mathrm{l}$ insulin (Sigma), $6.25 \mu \mathrm{g} /$ $\mathrm{ml}$ transferrin (Sigma), $1.25 \mu \mathrm{g} / \mathrm{ml}$ bovine serum albumin (BSA, Amresco). After being induced for 21 days, the cell mass was fixed with $4 \%$ paraformaldehyde at room temperature for staining and RNA isolation.

Cytochemical staining. The harvested cell mass was fixed in neutral-buffered formalin, embedded in paraffin, and sectioned (10- $\mu \mathrm{m}$ thick). The cross-sections were stained with toluidine blue and s-100 protein antigen.

RNA extraction. We used TRIzol reagent (Invitrogen) to isolate RNAs from culture cells (MSCs and chondrogenic differentiated MSCs from independent donor A, B, C) according to the manufacturer's instructions. The integrity and purity of total RNA was verified spectro-photometrically and by gel-electrophoresis on a formaldehyde denaturation gel.

miRNA microarray analysis. We examine global miRNA expression by miRNA microarray single-channel fluorescence chip (CapitalBio Corp. Beijing, China) that contains 743 probes in triplicate corresponding to current release of Sanger miRNA database (miRBase8.2, July 2006). The consistently expressed small nuclear RNA U6 was spotted as an internal control.

Procedures were performed as described previously $(23,24)$. Briefly, low-molecular-weight RNAs were enriched from $100 \mu \mathrm{g}$ total RNA [sample A, B, C (25)] with mirVana ${ }^{\mathrm{TM}}$ miRNA isolation kit (Ambion) and amplified with the NCode $^{\mathrm{TM}}$ miRNA amplification system (Invitrogen). Then, the amplified RNA was labeled with 5'-phosphate-cytidyluridyl-cy3-3' (Dharmacon, Lafayette, CO) with 2 units T4 RNA ligase (New England Biolabs, Ipswich, MA). The array was hybridized at $42^{\circ} \mathrm{C}$ overnight and washed with two consecutive washing solutions $\left(0.2 \% \mathrm{SDS}, 4 \mathrm{SSC}\right.$ at $42^{\circ} \mathrm{C}$ for $5 \mathrm{~min}$, and $0.2 \% \mathrm{SSC}$ for $5 \mathrm{~min}$ at room temperature). Then, using fluorescence scanning (LuxScan 10K/A, CapitalBio) and image analysis software (LuxScan 3.0, CapitalBio), digital signal intensities for each spot were obtained. Raw data were normalized on mean array intensity for inter-array comparison and analyzed using the Significance Analysis of Microarray (SAM, version 2.1, Stanford University, CA, USA) software (26), to determine differential expression of miRNAs between MSCs and chondrogenic differentiated MSCs.

Real-time quantitative PCR. The primers were designed according to miRNA sequences, and a universal PCR reverse primer (27). U6 small nuclear RNA gene was used as an internal control (28), and oligonucleotide primers were 5'-ctc gcttcggcagcaca-3' and 5'-aacgcttcacgaatttgcgt-3' .

Four miRNAs including hsa-miR-130b, hsa-miR-152, hsamiR-26b, and hsa-miR-28 selected by SAM in last step were subjected to real-time quantitative PCR. Their RT-PCR oligonucleotide primers were hsa-miR-130b: 5'-GTC GTATCCAGTGCAGGGTCCGAGGTATTCGCACTGGAT ACGACATGCCC-3' and 5'-CGCAGTGCAATGATGAA AGG-3'; hsa-miR-152: 5'-GTCGTATCCAGTGCAGGGT CCGAGGTATTCGCACTGGATACGACCCCAAG-3' and 5'-GTCGTCAGTGCATGACAGAACTT-3'; hsa-miR-26b: 5'-GTCGTATCCAGTGCAGGGTCCGAGGTATTCGCAC TGGATACGACACCTAT-3' and 5'-GCCGCTTCAAGTAA TTCAGGATA-3'; hsa-miR-28: 5'-GTCGTATCCAGTGCA GGGTCCGAGGTATTCGCACTGGATACGACCTCAAT-3' and 5'-CGGCAAGGAGCTCACAGTCTAT-3'. All these miRNA primers and U6 primer were designed using Primer Express version 5.0 (Applied Biosystems, Foster City, CA).

Following a previously described protocol (28), total RNA of MSCs and chondrogenic-differentiated MSCs from the third individual donor (sample C) were assayed with realtime RT-PCR. Briefly, procedures were conducted using Light Cycler PCR 1.2 (Roche), and LightCycler FastStart DNA Master SYBR Green I (Roche). Cycling parameters were $95^{\circ} \mathrm{C}$ for 10 min to denature DNA templates, then $95^{\circ} \mathrm{C}$ for $10 \mathrm{sec}$, and $60^{\circ} \mathrm{C}$ for $30 \mathrm{sec}$, with a final recording step of $74^{\circ} \mathrm{C}$ for $3 \mathrm{sec}$ to prevent any primer, 40 cycles in all. Melting curves were performed at $75-95^{\circ} \mathrm{C}$ and samples were also run on a $3 \%$ agarose gel to confirm specificity.

Target prediction. Three softwares available online were used for target prediction. They were targetScan (http://genes.mit. 
A

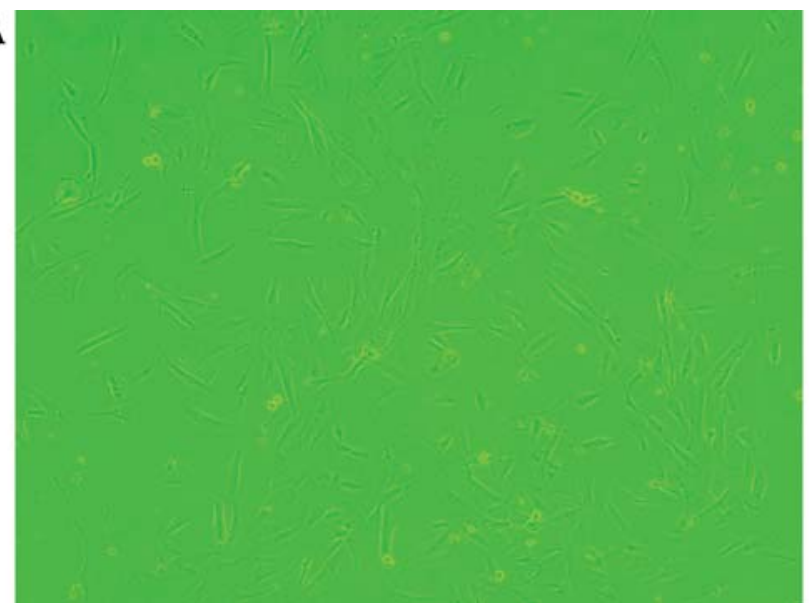

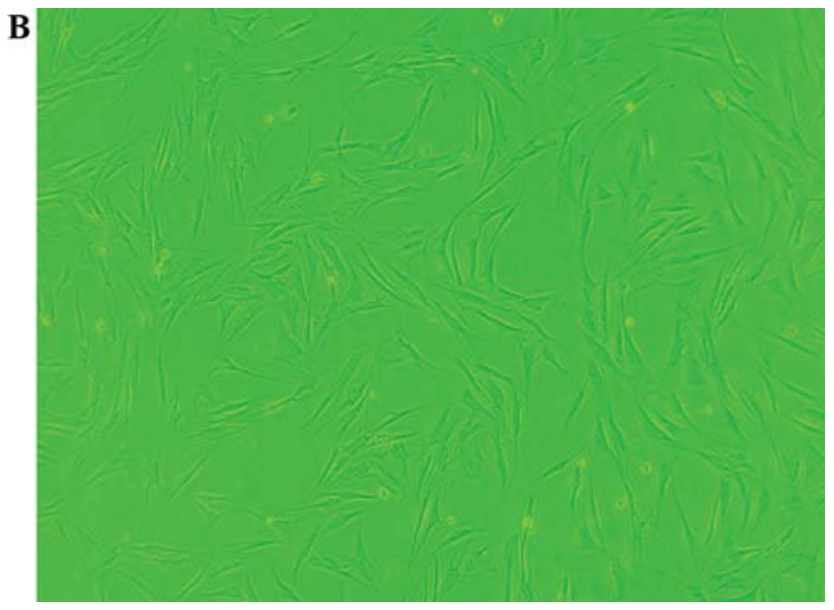

Figure 1. MSCs under inverted microscope (x100). (A) MSCs in primary culture at day 7, (B) MSCs in primary culture at day 14.
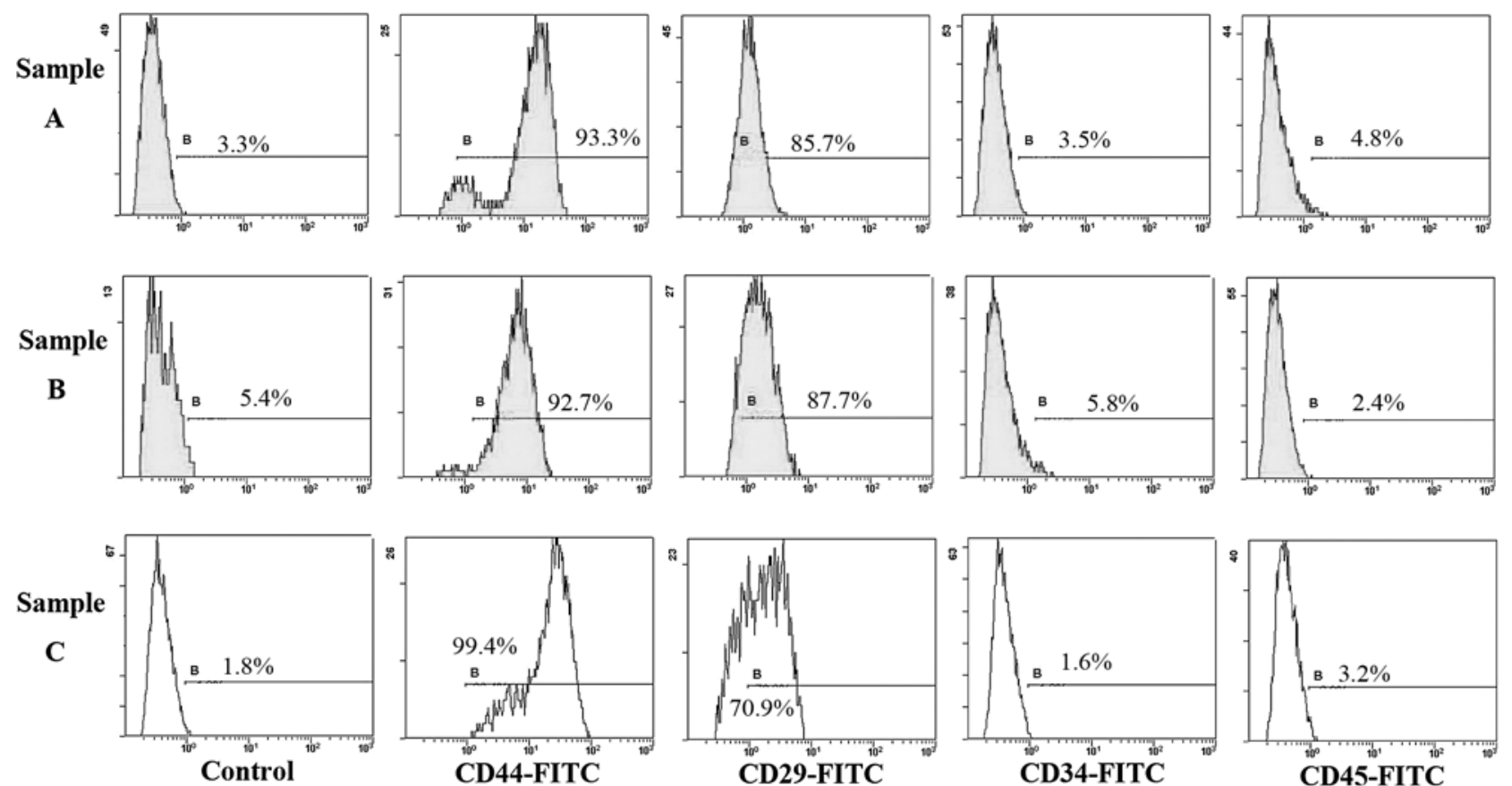

Figure 2. Surface marker analysis of MSCs.

edu/targetscan) (9,29), PicTar (http://pictar.bio.nyu.edu) (30), and miRanda (http://microrna.sanger.ac.uk/targets) (31). Candidate miRNAs up-regulated in chondrogenic differentiated MSCs were selected for target prediction.

\section{Results}

Characterization and phenotype of MSCs. Due to the lack of specific makers, MSC are usually defined by their plastic adherent growth, immunophenotype and differentiation potential (32). After seeded in flasks for $24 \mathrm{~h}$, most of the cells adhered to the flask and began to grow. After 3 or 5 days, the cells obtained a spindle shape and expanded (Fig. 1). We tested the surface antigens of MSCs by using flow cytometry, and the results demonstrate that these three MSC samples were all negative for the hematopoietic lineage markers CD34 and CD45, positive for CD29 and CD44 as expected (32-34) (Fig. 2).

Cytochemical staining of chondrogenic differentiated MSCs. The fixed cell masses prepared previously were stained by Toluidine blue and s-100 protein. The staining of s-100 protein (Fig. 3A) and Toluidine blue (Fig. 3B) were positive.

miRNA microarray analysis. RNA gel electrophoresis confirmed that the quality of the RNA of MSCs and chondrogenic differentiated MSCs was good. Using miRNA microarray technology, we detected the miRNA expression of MSCs and chondrogenic differentiated MSCs from sample A and B (Fig. 4).

SAM and unpaired comparison were performed to identify the differences in miRNA expression between MSCs and 

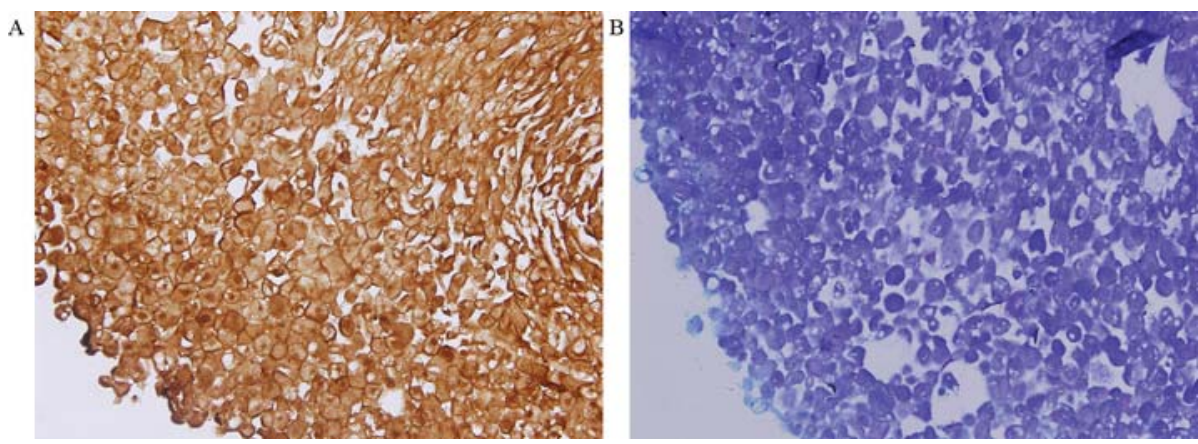

Figure 3. Staining of chondrogenic differentiated MSCs (x100). (A) Staining of Toluidine blue, (B) immunostaining of s-100 protein.
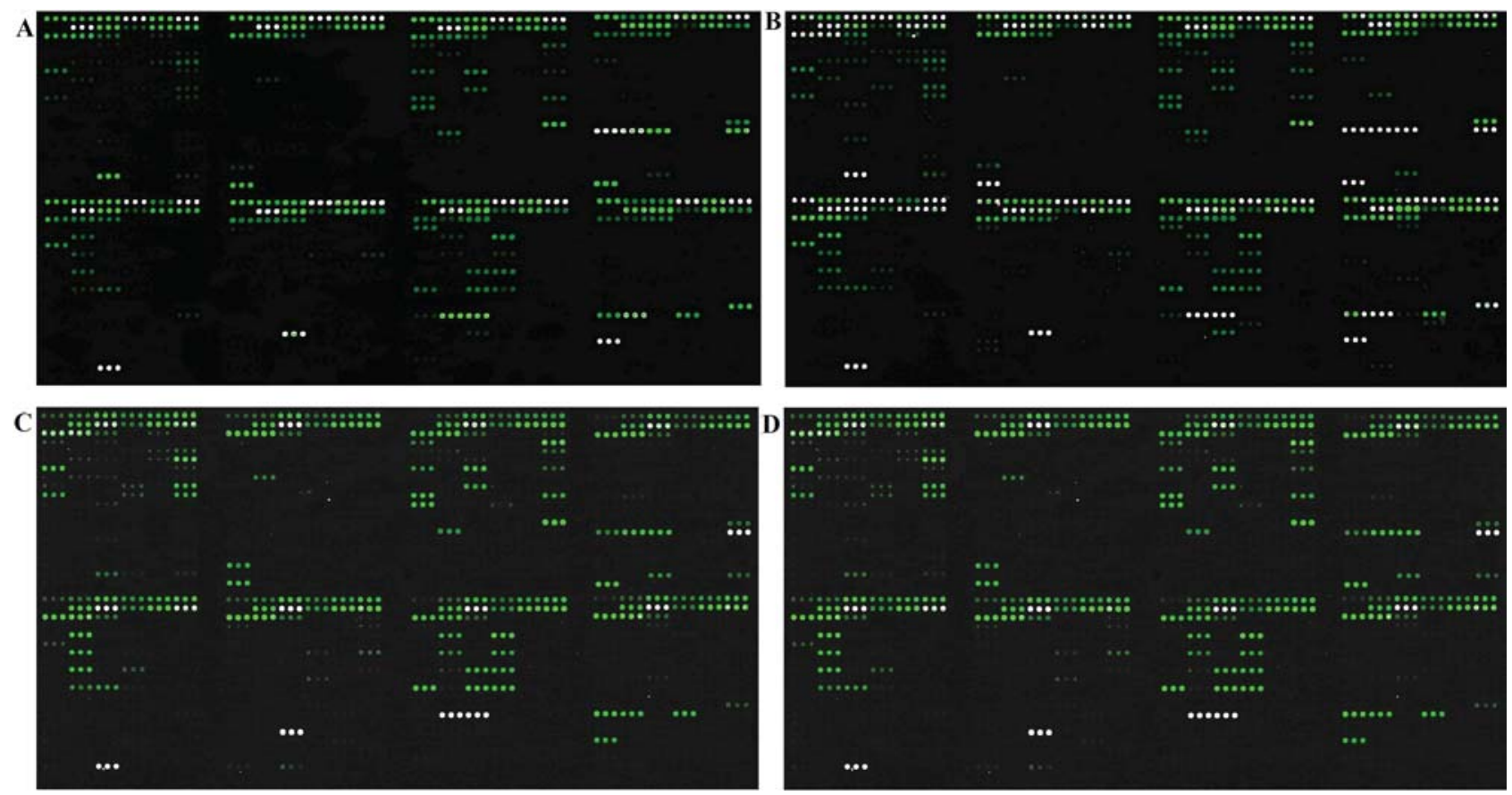

Figure 4. Microarray hybridization signals of MSCs and chondrogenic differentiated MSCs. The microarrays demonstrated miRNA expression profiles of MSCs (A) and chondrogenic differentiated MSCs (B) in sample A, MSCs (C) and chondrogenic differentiated MSCs (D) in sample B.

chondrogenic differentiated MSCs in each sample (FDR $\leq 5 \%$, fold change $\geq 2$ ). Comparing the two cell types, analysis of the microarray data showed that 26 miRNAs were overexpressed and 1 underexpressed in sample A, 7 miRNAs overexpressed and 2 underexpressed in sample B (Tables I and II). Comparing these two samples, we observed that 5 human miRNAs over-expressed chondrogenic differentiated MSCs in both samples. They were hsa-miR-130b, hsa-miR152, hsa-miR-28, hsa-miR-26b and hsa-miR-193b. However, none of the miRNAs in chondrogenic differentiated MSCs underexpressed in both samples (Table III).

Real-time PCR of miRNAs. To add reliability to these differentially-expressed miRNAs, we used real-time RT-PCR to verify the expression levels of the miRNAs (hsa-miR130b, hsa-miR-152, hsa-miR-28, hsa-miR-26b) in the third individual sample (sample $\mathrm{C}$ ).

The results showed that the expression levels for the 4 miRNAs were higher in chondrogenic differentiated MSCs

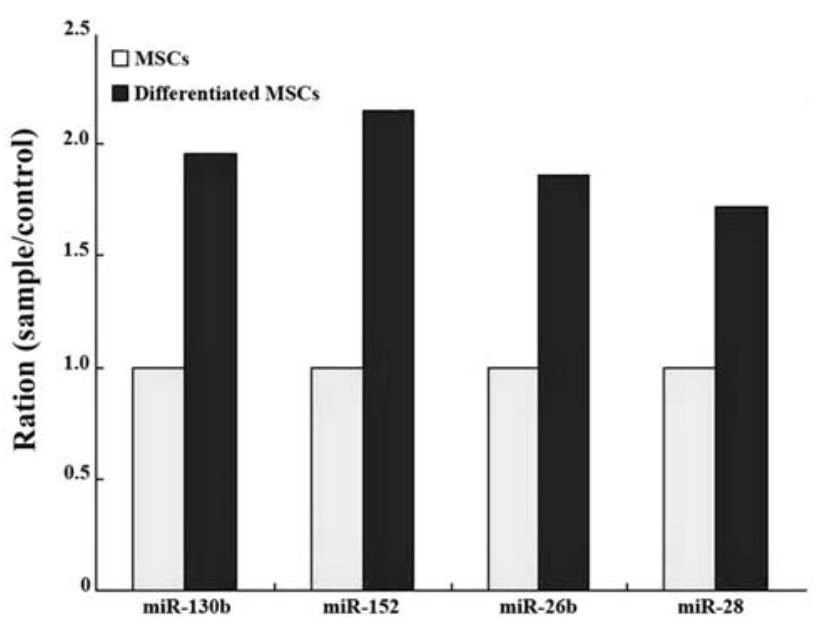

Figure 5. The histogram of real-time PCR results. miR-130b, miR-152, miR-26b and miR-28 are listed on the X-axis; the $\mathrm{Y}$-axis refers to the relative expression levels between MSCs (control) and chondrogenic differentiated MSCs (sample); and control expression is 1 . 
Table I. Differentially-expressed miRNAs between MSCs and chondrogenic differentiated MSCs in sample A.

\begin{tabular}{|c|c|c|c|}
\hline Gene name & Score $(d)$ & Fold change & q-value $(\%)$ \\
\hline \multicolumn{4}{|c|}{ Overexpressed miRNAs in chondrogenic differentiated MSCs } \\
\hline PREDICTED_MIR191 & 61.90756 & 10.22930984 & 0 \\
\hline hsa-miR-494 & 50.94587 & 9.384187345 & 0 \\
\hline PREDICTED_MIR189 & 44.50401 & 17.30665355 & 0 \\
\hline hsa-miR-23b & 42.56505 & 3.855811988 & 0 \\
\hline hsa-miR-24 & 41.70688 & 4.221921479 & 0 \\
\hline hsa-miR-101 & 37.33963 & 12.52892679 & 0 \\
\hline hsa-miR-27b & 35.93786 & 9.12200175 & 0 \\
\hline hsa-miR-143 & 29.75591 & 10.12670531 & 0 \\
\hline hsa-let-7f & 29.14949 & 8.489466293 & 0 \\
\hline hsa-miR-21 & 27.18485 & 4.774973191 & 0 \\
\hline hsa-miR-19a & 26.77491 & 8.773178739 & 0 \\
\hline hsa-miR-28 & 25.04472 & 7.731432434 & 0 \\
\hline hsa-let-7d & 24.7563 & 6.814207291 & 0 \\
\hline hsa-miR-196a & 24.39329 & 17.38690456 & 0 \\
\hline hsa-miR-153 & 23.58271 & 13.33122809 & 0 \\
\hline hsa-let-7e & 23.31158 & 5.197571623 & 0 \\
\hline hsa-miR-10b & 22.11271 & 13.2733231 & 0 \\
\hline hsa-let-7a & 21.6041 & 5.431683232 & 0 \\
\hline hsa-miR-296 & 21.3643 & 4.491348558 & 0 \\
\hline hsa-miR-34a & 21.32207 & 23.89235671 & 0 \\
\hline hsa-let-7b & 21.28517 & 5.42947065 & 0 \\
\hline hsa-miR-125b & 21.17034 & 2.633324849 & 0 \\
\hline hsa-miR-26b & 20.76998 & 7.953414823 & 0 \\
\hline hsa-miR-34b & 20.73275 & 24.57993313 & 0 \\
\hline hsa-miR-127 & 20.6463 & 4.961294298 & 0 \\
\hline hsa-miR-125a & 20.55137 & 6.950404646 & 0 \\
\hline \multicolumn{4}{|c|}{ Underexpressed miRNAs in chondrogenic differentiated MSCs } \\
\hline hsa-miR-122a & -74.2364 & 0.004226096 & $\mathbf{0}$ \\
\hline
\end{tabular}

Underexpressed miRNAs are in bold.

than MSCs, demonstrating that the PCR results were in concordance with the microarray analysis (Table IV and Fig. 5).

Putative target prediction for miRNAs. With the online software described previously, we predicted the putative targets for hsa-miR-130b, hsa-miR-152, hsa-miR-28, hsamiR-26b, and we obtained several possible targets for these four miRNAs. Many are related to bone and cartilage formation, sulfation of chondroitin, and signal transduction. We listed some representative possible targets in Table V.

\section{Discussion}

There are a variety of techniques to detect the expression of miRNAs in tissues. Among these techniques, microarray assay provides a high-flux method for detecting miRNA expression simultaneously (35). While, for its false discovery rate (FDR), the microarray results should be validated by using Northern blots or real-time PCR. In this study, we obtained miRNA expression maps of MSCs and chondrogenic differentiated MSCs using microarrays, 5 miRNAs (hsa-miR-130b, hsamiR-152, hsa-miR-28, hsa-miR-26b, hsa-miR-193b) were expressed significantly differently between them by SAM assay. Of these 5 different miRNAs, 4 miRNAs (hsa-miR130b, hsa-miR-152, hsa-miR-28, hsa-miR-26b) were isolated from the third donor and validated by real-time PCR, which added credibility to the microarray results. In this step, we observed the variability between the two donors. For example, we detected 78 human miRNAs up-regulated in sample A, but 7 miRNAs in sample B, and the overlap between them was 5. The down-regulated human miRNAs was 1 in sample A, 2 in sample B, and there was no overlap. These differences could be caused by the variability of MSCs $(5,36)$. Another example probably for the variability is that some miRNAs which have been reported to be related to 
Table II. Differentially-expressed miRNAs between MSCs and chondrogenic differentiated MSCs in sample B.

\begin{tabular}{|c|c|c|c|}
\hline miRNA & Score $(d)$ & Fold change & q-value $(\%)$ \\
\hline \multicolumn{4}{|c|}{ Overexpressed miRNAs in chondrogenic differentiated MSCs } \\
\hline hsa-miR-572 & 13.15153 & 3.093737687 & 0 \\
\hline hsa-miR-28 & 9.093153 & 2.38822041 & 0 \\
\hline hsa-miR-193b & 8.196323 & 2.587382493 & 0 \\
\hline hsa-miR-130b & 7.976752 & 2.950776614 & 0 \\
\hline hsa-miR-152 & 6.313401 & 2.247640546 & 0 \\
\hline hsa-miR-26b & 5.359322 & 2.021033713 & 0 \\
\hline hsa-miR-560 & 4.491367 & 2.079951506 & 0 \\
\hline \multicolumn{4}{|c|}{ Underexpressed miRNAs in chondrogenic differentiated MSCs } \\
\hline PREDICTED_MIR189 & -15.4503 & 0.315047598 & $\mathbf{0}$ \\
\hline hsa-miR-424 & -9.75853 & 0.229614492 & $\mathbf{0}$ \\
\hline
\end{tabular}

Underexpressed miRNAs are in bold.

Table III. miRNAs overexpressed in chondrogenic differentiated MSCs in both sample A and sample B.

\begin{tabular}{lcc}
\hline & \multicolumn{2}{c}{ Fold change } \\
\cline { 2 - 3 } Gene name & Sample A & Sample B \\
\hline hsa-miR-130b & 2.429655338 & 2.950776614 \\
hsa-miR-152 & 10.65679325 & 2.247640546 \\
hsa-miR-26b & 7.953414823 & 2.021033713 \\
hsa-miR-193b & 4.111352285 & 2.587382493 \\
hsa-miR-28 & 7.731432434 & 2.38822041 \\
\hline
\end{tabular}

cartilage did not demonstrate differential expression in this study $(22,37,38)$.

miRNAs play the regulatory roles by binding target sites and modulating the translation of specific mRNA. Therefore, bioinformatic methods based on sequence similarity between targets and miRNAs can be used to predict the potential target genes of miRNAs, which can provide guidance for further analysis of miRNA functions (39). Herein we predicted some potential genes of the validated miRNAs by using TargetScan 5.1. Among the predicted genes, there are several genes associated with collagen proteins such as COL2A1, COL4A1, and COL6A1. These genes encode their correspondent type collagen, and their mutations usually result in pathologic skeletal disorders, especially chondrocytes. For example, COL2A1 predicted by hsa-miR-152 encodes type II collagen which is the main component of articular cartilage (40), and the gene mutations are associated with achondrogenesis, chondrodysplasia, and early onset familial osteoarthritis.

The gene COL10A1 predicted by hsa-miR-26b encodes the type $\mathrm{X}$ collagen, a short chain collagen specifically expressed by hypertrophic chondrocytes during endochondral ossification (41). Type X collagen plays an important role during endochondral ossification, and loss of its function caused impairment of endochondral ossification and skeletal
Table IV. miRNAs in MSCs and chondrogenic differentiated MSCs verified by real-time RT-PCR.

\begin{tabular}{lcrrr}
\hline Name & E & ${ }^{a} \mathrm{CP}$ & $\begin{array}{c}\text { Ratio before } \\
\text { normalization }\end{array}$ & $\begin{array}{c}\text { Ratio after } \\
\text { normalization }\end{array}$ \\
\hline U6 & 1.866 & -0.33 & 0.813952683 & \\
hsa-miR-130b & 1.863 & 0.75 & 1.594628938 & 1.959117492 \\
hsa-miR-152 & 1.875 & 0.89 & 1.749730379 & 2.149670879 \\
hsa-miR-26b & 1.88 & 0.66 & 1.516855395 & 1.863567044 \\
hsa-miR-28 & 1.844 & 0.55 & 1.400130461 & 1.720161983 \\
\hline
\end{tabular}

Control, MSCs; sample, osteo-differentiated MSCs. ${ }^{\text {a }} \mathrm{CP}$, (control-sample) crossing point; ratio $=$ sample/control.

growth in mice (42-44). Therefore, the mutations of COL10A1 can cause a severe skeletal disorder called Schmid-type metaphyseal chondrodysplasia $(45,46)$. Upon these findings, we can see these two genes have a close relationship with the cartilage development, therefore we predict that the miRNAs associated with these putative collagen-related genes, such as hsa-miR-152 and hsa-miR-26b, probably play some roles in the procedure of endochondral ossification and skeletal growth.

In addition, there are a group of BMP (bone morphogenetic protein) related genes such as BMP3 (bone morphogenetic protein type 3), BMPR1B (bone morphogenetic protein receptor type IB), BMPR2 (bone morphogenetic protein receptor type II), which are predicted by hsa-miR-152 and hsa-miR-130b. Of those genes, BMP3 belongs to the transforming growth factor- $\beta$ (TGFB) superfamily. BMPs are involved in endochondral bone formation and embryogenesis (46-48). Genes of BMPR1B and BMPR2 encode the bone morphogenetic protein (BMP) receptors. CHST3 (chondroitin sulfotransferase 3) and CHSY1 (chondroitin sulfate synthase 1) predicted by hsa-miR-26b are associated with chondroitin synthesis. 
Table V. Putative target genes for miRNAs.

\begin{tabular}{lll}
\hline Gene name & \multicolumn{1}{c}{ Representative possible targets } & Function \\
\hline hsa-miR-130b & BMPR2 (bone morphogenetic protein receptor, type II) & Bone formation \\
& BMP3 (bone morphogenetic protein, type III) & Bone formation \\
& BMPR1B (bone morphogenetic protein receptor, type IB) & Bone formation \\
& COL19A1 (collagen, type XIX, $\alpha$ 1) & Collagens fibril-forming \\
hsa-miR-152 & BMP3 (bone morphogenetic protein, type III) & Bone formation \\
& COL4A1 (collagen, type IV, $\alpha$ 1) & Cartilage formation \\
& COL2A1 (collagen, type II, $\alpha$ 1) & Cartilage formation \\
hsa-miR-26b & COL6A1 (collagen, type IV, $\alpha$ 1) & Cartilage formation \\
& COL10A1 (collagen, type X, $\alpha 1)$ & Endochondral ossification \\
& CHST3 (chondroitin 6 sulfotransferase 3) & Sulfation of chondroitin \\
& CHSY1 (chondroitin sulfate synthase 1) & Sulfation of chondroitin \\
& CILP (cartilage intermediate layer protein) & Cartilage formation \\
& IGF1 (insulin-like growth factor 1) & Growth and development \\
& SMAD1 (mothers against DPP homolog 1) & Signal transduction \\
hsa-miR-28 & IGF2BP1 (insulin-like growth factor 2 mRNA binding protein 1) & Regulating IGF2 translation
\end{tabular}

CHST3 encodes an enzyme which catalyzes the sulfation of chondroitin, a proteoglycan involved in cell migration and differentiation, and mutations in this gene are associated with spondylepiphyseal dysplasia and humerospinal dysostosis $(49,50)$. CHSY1 synthesizes chondroitin sulfate (51). Chondroitin sulfate and dermatan sulfate chains play structural roles in cartilage bone, and other connective tissues (52-54). Another predicted gene by hsa-miR-26b is CILP (cartilage intermediate layer protein), and it encodes the cartilage intermediate layer protein (CILP), which increases in early osteo-arthritis cartilage (55). IGF-1 (insulin-like growth factor I) predicted by hsa-miR-26b was reported to promote the differentiation of MSCs into chondrocytes in combination with TGF-ß (56).

In conclusion, we applied microarrays to detect the miRNAs in human MSCs and their chondrogenic differentiated cells and obtained 4 specific miRNA in the latter, which were validated by real-time PCR. Due to lack of bone marrow donors, only two samples were tested on microarrays, but we employed a third sample to verify the results obtained from two previous samples by real-time PCR, and the PCR results were consistent with the SAM results. For further confirmation of the obtained results, we will enlarge the sample size of MSCs and continue to study the differently expressed miRNA functions.

\section{Acknowledgements}

This work is supported by National Natural Science Foundation of China, Project number: 30672143.

\section{References}

1. Reyes M, Lund T, Lenvik T, Aguiar D, Koodie L and Verfaillie CM: Purification and ex vivo expansion of postnatal human marrow mesodermal progenitor cells. Blood 98: 2615-2625, 2001.
2. Jiang Y, Jahagirdar BN, Reinhardt RL, et al: Pluripotency of mesenchymal stem cells derived from adult marrow. Nature 418: 41-49, 2002

3. Tocci A and Forte L: Mesenchymal stem cell: use and perspectives. Hematol J 4: 92-96, 2003.

4. Le Blanc K and Pittenger M: Mesenchymal stem cells: progress toward promise. Cytotherapy 7: 36-45, 2005.

5. Goff LA, Boucher S, Ricupero CL, et al: Differentiating human multipotent mesenchymal stromal cells regulate microRNAs: prediction of microRNA regulation by PDGF during osteogenesis. Exp Hematol 36: 1354-1369, 2008.

6. Kloosterman WP and Plasterk RH: The diverse functions of microRNAs in animal development and disease. Dev Cell 11: 441-450, 2006

7. Bartel DP: MicroRNAs: genomics, biogenesis, mechanism, and function. Cell 116: 281-297, 2004.

8. Lee RC, Feinbaum RL and Ambros V: The C. elegans heterochronic gene lin-4 encodes small RNAs with antisense complementarity to lin-14. Cell 75: 843-854, 1993.

9. Lewis BP, Shih IH, Jones-Rhoades MW, Bartel DP and Burge CB: Prediction of mammalian microRNA targets. Cell 115: 787-798, 2003.

10. Wienholds E, Kloosterman WP, Miska E, et al: MicroRNA expression in zebrafish embryonic development. Science 309: 310-311, 2005

11. Hatfield SD, Shcherbata HR, Fischer KA, Nakahara K, Carthew RW and Ruohola-Baker H: Stem cell division is regulated by the microRNA pathway. Nature 435: 974-978, 2005.

12. Esau C, Kang X, Peralta E, et al: MicroRNA-143 regulates adipocyte differentiation. J Biol Chem 279: 52361-52365, 2004.

13. Zhao Y, Samal E and Srivastava D: Serum response factor regulates a muscle-specific microRNA that targets Hand2 during cardiogenesis. Nature 436: 214-220, 2005.

14. Kuwabara T, Hsieh J, Nakashima K, Taira K and Gage FH: A small modulatory dsRNA specifies the fate of adult neural stem cells. Cell 116: 779-793, 2004.

15. Chen CZ, Li L, Lodish HF and Bartel DP: MicroRNAs modulate hematopoietic lineage differentiation. Science 303: 83-86, 2004.

16. Tang F, Hajkova P, Barton SC, Lao K and Surani MA: MicroRNA expression profiling of single whole embryonic stem cells. Nucleic Acids Res 34: E9, 2006.

17. Chen YJ, Min J, Shang CZ, et al: MicroRNA differential expression profile during differentiation of embryonic stem cells towards hepatocytes induced by sodium butyrate. Zhongguo Yi Xue Ke Xue Yuan Xue Bao 30: 469-473, 2008. 
18. Ivey KN, Muth A, Arnold J, et al: MicroRNA regulation of cell lineages in mouse and human embryonic stem cells. Cell Stem Cell 2: 219-229, 2008.

19. Houbaviy HB, Murray MF and Sharp PA: Embryonic stem cellspecific MicroRNAs. Dev Cell 5: 351-358, 2003.

20. Suh MR, Lee Y, Kim JY, et al: Human embryonic stem cells express a unique set of microRNAs. Dev Biol 270: 488-498, 2004.

21. Mizuno Y, Yagi K, Tokuzawa Y, et al: miR-125b inhibits osteoblastic differentiation by down-regulation of cell proliferation. Biochem Biophys Res Commun 368: 267-272, 2008.

22. Tuddenham L, Wheeler G, Ntounia-Fousara S, et al: The cartilage specific microRNA-140 targets histone deacetylase 4 in mouse cells. FEBS Lett 580: 4214-4217, 2006.

23. Yan N, Lu Y, Sun H, et al: A microarray for microRNA profiling in mouse testis tissues. Reproduction 134: 73-79, 2007.

24. Liao R, Sun J, Zhang L, et al: MicroRNAs play a role in the development of human hematopoietic stem cells. J Cell Biochem 104: 805-817, 2008.

25. Thomson JM, Parker J, Perou CM and Hammond SM: A custom microarray platform for analysis of microRNA gene expression. Nat Methods 1: 47-53, 2004.

26. He H, Jazdzewski K, Li W, et al: The role of microRNA genes in papillary thyroid carcinoma. Proc Natl Acad Sci USA 102 19075-19080, 2005.

27. Chen C, Ridzon DA, Broomer AJ, et al: Real-time quantification of microRNAs by stem-loop RT-PCR. Nucleic Acids Res 33: E179, 2005.

28. Schmittgen TD, Jiang J, Liu Q and Yang L: A high-throughput method to monitor the expression of microRNA precursors. Nucleic Acids Res 32: E43, 2004.

29. Rajewsky N and Socci ND: Computational identification of microRNA targets. Dev Biol 267: 529-535, 2004.

30. Krek A, Grun D, Poy MN, et al: Combinatorial microRNA target predictions. Nat Genet 37: 495-500, 2005.

31. John B, Enright AJ, Aravin A, Tuschl T, Sander C and Marks DS: Human MicroRNA targets. PLoS Biol 2: E363, 2004.

32. Dominici M, Le Blanc K, Mueller I, et al: Minimal criteria for defining multipotent mesenchymal stromal cells. The International Society for Cellular Therapy position statement. Cytotherapy 8: 315-317, 2006.

33. Pittenger MF, Mackay AM, Beck SC, et al: Multilineage potential of adult human mesenchymal stem cells. Science 284 143-147, 1999.

34. Wagner W, Wein F, Seckinger A, et al: Comparative characteristics of mesenchymal stem cells from human bone marrow, adipose tissue, and umbilical cord blood. Exp Hematol 33: 1402-1416, 2005.

35. Barad O, Meiri E, Avniel A, et al: MicroRNA expression detected by oligonucleotide microarrays: system establishment and expression profiling in human tissues. Genome Res 14: 2486-2494, 2004.

36. Lakshmipathy U and Hart RP: Concise review: MicroRNA expression in multipotent mesenchymal stromal cells. Stem Cells 26: 356-363, 2008.

37. Ohgawara T, Kubota S, Kawaki H, et al: Regulation of chondrocytic phenotype by micro RNA 18a: involvement of $\mathrm{Ccn} 2 / \mathrm{Ctgf}$ as a major target gene. FEBS Lett 583: 1006-1010, 2009.

38. Lin EA, Kong L, Bai XH, Luan Y and Liu CJ: miR-199a, a bone morphogenic protein 2 responsive microRNA, regulates chondrogenesis via direct targeting to Smad1. J Biol Chem 284: 11326-11335, 2009.
39. Bentwich I: Prediction and validation of microRNAs and their targets. FEBS Lett 579: 5904-5910, 2005

40. Structural and contractile proteins. Part D. Extracellular matrix. Methods Enzymol 144: 1-561, 1987.

41. Linsenmayer TF, Long F, Nurminskaya M, Chen Q and Schmid TM: Type X collagen and other up-regulated components of the avian hypertrophic cartilage program. Prog Nucleic Acid Res Mol Biol 60: 79-109, 1998.

42. Rosati R, Horan GS, Pinero GJ, et al: Normal long bone growth and development in type $\mathrm{X}$ collagen-null mice. Nat Genet 8: 129-135, 1994.

43. Kwan KM, Pang MK, Zhou S, et al: Abnormal compartmentalization of cartilage matrix components in mice lacking collagen X: implications for function. J Cell Biol 136: 459-471, 1997.

44. Jacenko O, Chan D, Franklin A, et al: A dominant interference collagen $\mathrm{X}$ mutation disrupts hypertrophic chondrocyte pericellular matrix and glycosaminoglycan and proteoglycan distribution in transgenic mice. Am J Pathol 159: 2257-2269, 2001.

45. Warman ML, Abbott M, Apte SS, et al: A type X collagen mutation causes Schmid metaphyseal chondrodysplasia. Nat Genet 5: 79-82, 1993.

46. Chan D and Jacenko O: Phenotypic and biochemical consequences of collagen $\mathrm{X}$ mutations in mice and humans. Matrix Biol 17: 169-184, 1998.

47. Tsumaki $\mathrm{N}$ and Yoshikawa $\mathrm{H}$ : The role of bone morphogenetic proteins in endochondral bone formation. Cytokine Growth Factor Rev 16: 279-285, 2005.

48. Wozney JM: The bone morphogenetic protein family: multifunctional cellular regulators in the embryo and adult. Eur J Oral Sci 106 (Suppl 1): 160-166, 1998.

49. Hermanns P, Unger S, Rossi A, et al: Congenital joint dislocations caused by carbohydrate sulfotransferase 3 deficiency in recessive Larsen syndrome and humero-spinal dysostosis. Am J Hum Genet 82: 1368-1374, 2008.

50. Thiele H, Sakano M, Kitagawa H, et al: Loss of chondroitin 6-O-sulfotransferase-1 function results in severe human chondrodysplasia with progressive spinal involvement. Proc Natl Acad Sci USA 101: 10155-10160, 2004

51. Kitagawa H, Izumikawa T, Uyama T and Sugahara K: Molecular cloning of a chondroitin polymerizing factor that cooperates with chondroitin synthase for chondroitin polymerization. J Biol Chem 278: 23666-23671, 2003.

52. Kawashima H, Atarashi K, Hirose M, et al: Oversulfated chondroitin/dermatan sulfates containing GlcAbeta1/IdoAalpha13GalNAc(4,6-O-disulfate) interact with L- and P-selectin and chemokines. J Biol Chem 277: 12921-12930, 2002.

53. Morgenstern DA, Asher RA and Fawcett JW: Chondroitin sulphate proteoglycans in the CNS injury response. Prog Brain Res 137: 313-332, 2002.

54. Bechard D, Gentina T, Delehedde M, et al: Endocan is a novel chondroitin sulfate/dermatan sulfate proteoglycan that promotes hepatocyte growth factor/scatter factor mitogenic activity. J Biol Chem 276: 48341-48349, 2001

55. Lorenzo P, Bayliss MT and Heinegard D: A novel cartilage protein (CILP) present in the mid-zone of human articular cartilage increases with age. J Biol Chem 273: 23463-23468, 1998.

56. Longobardi L, O'Rear L, Aakula S, et al: Effect of IGF-I in the chondrogenesis of bone marrow mesenchymal stem cells in the presence or absence of TGF-beta signaling. J Bone Miner Res 21: 626-636, 2006 